\title{
A Buried Cavity Backed Slot Antenna for Agriculture and Infrastructure Monitoring
}

\author{
Arslan Nizami \\ School of Engineering and Built \\ Environment \\ Griffith University \\ Brisbane, Australia \\ arslan.nizami@griffithuni.edu.au \\ Mohamed Radwan \\ School of Engineering and Built \\ Environment \\ Griffith University \\ Brisbane, Australia \\ mohamed.radwan@griffithuni.edu.au
}

\author{
Yana Salchak \\ School of Engineering and Built \\ Environment \\ Griffith University \\ Brisbane, Australia \\ iana.salchak@griffith.edu.au \\ Hugo G. Espinosa \\ School of Engineering and Built \\ Environment \\ Griffith University \\ Brisbane, Australia \\ h.espinosa@griffith.edu.au
}

\author{
Noor Albadri \\ School of Engineering and Built \\ Environment \\ Griffith University \\ Brisbane, Australia \\ n.al-badri@griffith.edu.au \\ David V. Thiel \\ School of Engineering and Built \\ Environment \\ Griffith University \\ Brisbane, Australia \\ d.thiel@griffith.edu.au
}

\begin{abstract}
While the earth provides a relative secure environment in the event of flood, fires and storm events, the design of antennas which operate satisfactorily to a receiver on or above the ground has been a design challenge. A cavitybacked slot antenna previously used for biomedical applications was modified for subsurface propagation at $433 \mathrm{MHz}$ at shallow depths in soil. A $433 \mathrm{MHz}+10 \mathrm{dBm}$ beacon located in an aluminium box $(163 \times 114 \times 42 \mathrm{~mm})$ with a thin $(1 \mathrm{~mm}$ width $)$ slot buried to a depth of $100 \mathrm{~mm}$. Vertical electric field measurements were made on the surface of the earth from the antenna buried in moist lawn-covered soil. The antenna was placed below the grassed surface with the slot directing radiation horizontally into the soil. Propagation across the surface suffered a loss of $0.53 \mathrm{~dB} / \mathrm{m}$. This technology shows significant promise in the case of sensors buried in soil.
\end{abstract}

Keywords—slot antenna, UHF, RSSI, surface propagation.

\section{INTRODUCTION}

The propagation of radio waves in forests and woodlands has been studied by Tamir at RF frequencies $(1-100 \mathrm{MHz})$ [1] where the top of the canopy and the earth form the bounds of a waveguide which supports a lateral wave and the sky wave is reflected from the ionosphere. At these frequencies the vegetation was assumed to have uniform electromagnetic properties $\left(1.01<\varepsilon_{\mathrm{r}}<1.5,10^{-3}>\sigma>10^{-4} \mathrm{~S} / \mathrm{m}\right.$ where $\varepsilon_{\mathrm{r}}$ is the relative permittivity and $\sigma$ is the conductivity).

Underground propagation at $433 \mathrm{MHz}$ has been explored by numerous authors [2-5] using wire antennas for different applications such as agriculture, soil monitoring and mine environment. Communications from underground infrastructure is of increasing interest to monitor water pipes etc [6] and for precision agriculture applications monitoring soil nutrients and moisture [7].

In this paper we propose a novel idea of using slot antenna model where a monopole antenna is used inside an aluminium box. This configuration offers mechanical, moisture and thermal protection under extreme circumstances.

The line of sight ("direct wave") is more than $60 \mathrm{~dB}$ less than the lateral wave. The electric field strength $E(d)$ increases at small distances $d$ above the earth's surface (so called "height gain effect"). The electric field $E(d)$ across the surface given by the equation:

$$
E(d)=E_{0} \frac{e^{-\alpha d}}{d}
$$

where $\alpha$ is the attenuation coefficient and $E_{0}$ is the initial field strength. This relationship was found to be suitable for both vertical and horizontal polarisation. The path loss over $1 \mathrm{~km}$ at $400 \mathrm{MHz}$ was estimated to be approximately $130 \mathrm{~dB}$. The depolarisation is predicted using the lateral wave model [1]. A vertically polarised transmitter will yield both polarisations in the far field, however, a conducting earth plane will have a very small horizontal component at the earth's surface.

Lateral waves have been the subject of ray path analysis for a buried and an above ground transmitter with both vertical and horizontal polarisations $[8,9]$, and the surface interference effect from a buried transmitter was modelled and measured at $433 \mathrm{MHz}$ over beach sand in-situ with no vegetation $\left(\varepsilon_{\mathrm{r}}=\right.$ 2.13, $\sigma=10^{-4} \mathrm{~S} / \mathrm{m}$ ) [10]. However, if the conductivity is too high $\left(\varepsilon_{\mathrm{r}} \varepsilon_{0}<\omega \sigma\right.$ where $\varepsilon_{0}$ is the permittivity of free space), this interference pattern disappears. This was evident in ocean measurements at $433 \mathrm{MHz}$ [11] where the transmitting antenna was located below the surface of the water in an airfilled plastic cylinder.

Fire has a significant effect in a forest. The most obvious change to a forest from before to after a substantial fire is the removal of foliage and the reduction in thin twigs and branches. Smaller trees and even large trees may be totally consumed or fall to the ground as glowing coals. The removal of foliage will reduce the radio attenuation coefficient. An additional effect is the removal of organic matter and the drying of the surface soil, however this effect is not likely to exceed a depth of $5 \mathrm{~cm}$ [12]. The removal of organic matter and soil moisture will greatly reduce the conductivity of the upper layer to this depth. Electronic instrumentation (transmitters and receivers) are therefore well protected from the very high temperatures observed in and above the flames of a wild fire.

\section{METHODS}

\section{Slot antenna design and radio beacons}

A $433 \mathrm{MHz}$ radio beacon $[10,11]$ developed in-house has a transmit power of $+10 \mathrm{dBm}$ and is capable of logging the signal strength (RSS) received by a second unit 10 times each second. The master beacon with a monopole antenna (length $30 \mathrm{~mm}$ ) was positioned inside an aluminium box (internal dimensions $163 \times 114 \times 42 \mathrm{~mm}$ ) to couple into the lowest 
$\mathrm{TE}_{110}$ resonant mode of the cavity. A narrow ( $1 \mathrm{~mm}$ wide) slot in the smallest face (length $114 \mathrm{~mm}$ ) ensured that the E field was perpendicular to the slot for maximum emitted radiation (Figure 1). The completed cavity-based slot antenna with master transmitter unit was buried to a depth of $100 \mathrm{~mm}$ (the distance of the top of the box to the ground surface) (Figure 2). The receiver was an identical unit and has a $178 \mathrm{~mm}$ monopole antenna. The cavity-backed slot antenna is a variation to the designs previously reported for in-body and off-body communications $[13,14]$.

The results from the buried transmitter were compared with transmission results for two above ground monopole antennas on the earth's surface. This "ground-wave propagation" has been the subject of numerous studies and includes analytical formulations by Sommerfeld and Norton $[15,16]$. When the earth is not perfectly conducting, there is a radiation pattern minimum in the horizontal direction for vertical polarisation as the reflection coefficient is -1 resulting in radiation cancellation (see [15] Figure 16-9). In this experiment the ground wave attenuation for antennas close to the surface was compared using the attenuation rate $\alpha$ in $\mathrm{dB} / \mathrm{m}$. The buried transmitter with a horizontal slot is shown in Figure 2 and measurements were made across the grassed surface.

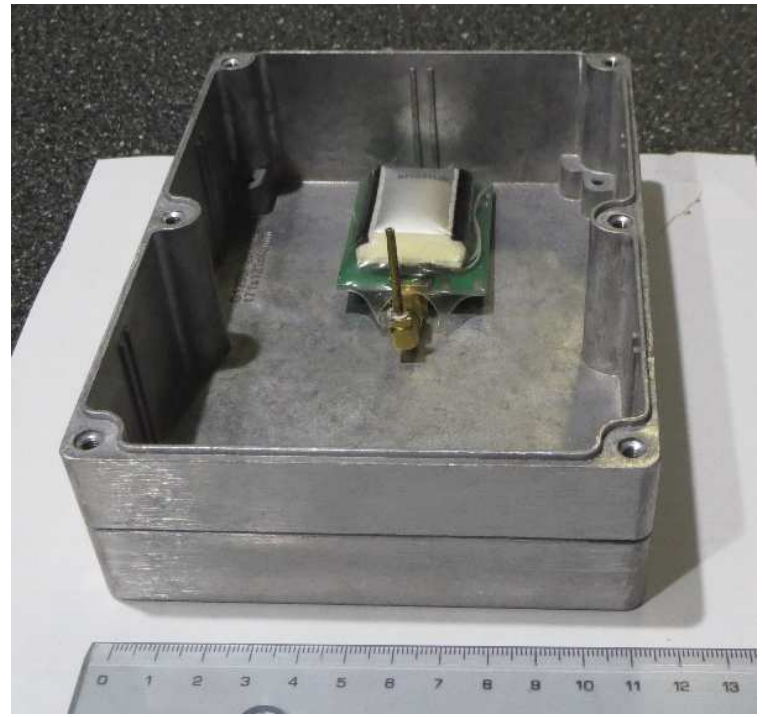

Fig. 1. The $433 \mathrm{MHz}$ cavity backed slot antenna with dimensions $163 \times 114 \times 42 \mathrm{~mm}$. The slot at the front is $1 \mathrm{~mm}$ wide and extends across the width of the aluminium box. The beacon transmitter with $30 \mathrm{~mm}$ monopole is positioned in the centre of the box.

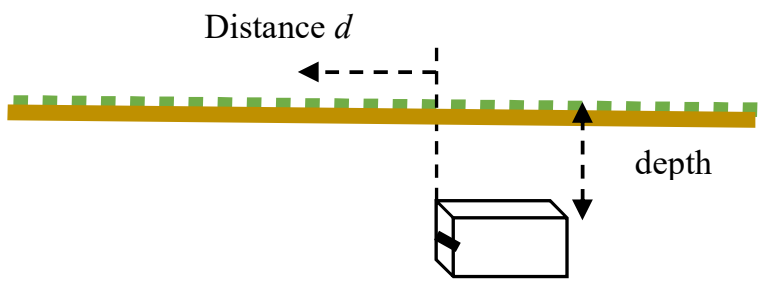

Fig. 2. Buried horizontal box (depth $100 \mathrm{~mm}$ ) below a flat, grassed surface. The end slot was horizontal for the surface propagation measurements in $0.5 \mathrm{~m}$ steps. The front to back ratio across the surface was measured at $5 \mathrm{~dB}$ and the maximum received signal was immediately above the slot.

\section{RESULTS}

\section{Experimental measurements}

The received electric field at the surface of the earth was vertically polarised (i.e., normal to the earth's surface). This is the opposite polarisation [10] from the radiation from a horizontally polarised transmitter buried in a low loss material (dry beach sand).

The electric field $E(d)$ converted to the received signal strength in $\mathrm{dBm}$ was fitted to the spherical wave equation (1) for distance $d$ and with attenuation coefficient $\alpha$ given by the equation:

$20 \log _{10}(E(d))=20 \log _{10}\left(E_{0}\right)-8.686 \alpha d-20 \log _{10} d(2)$

Rearranging this equation gives:

$20 \log _{10}(E(d))+20 \log _{10} d=20 \log _{10}\left(E_{0}\right)-8.686 \alpha d$ (3)

The LHS of (3) versus $d$ should be linear providing measurements are in the far field of the antennas and the received signal is above the noise level.

Figure 3 shows the received signal strength as a function of horizontal distance from the buried slot antenna, this is represented by the measured data and a linear fit for both the above and below ground transmitter locations using (3). Note that the Pearson's correlation coefficient $r^{2}$ is 0.89 and 0.90 for the above ground and below ground transmitter locations, respectively. The vertical electric field dominates the propagation so that all measurements were made using the same vertical monopole antenna. At ground level the received signal is a minimum, and it increases with height $[15,16]$. The above ground transmission path has indications of a foreground interference with a series of undulations (see Fig. 3).

The same $+10 \mathrm{~dB}$ transmitter circuit was used for both above and below the ground. Table 1 shows that at $100 \mathrm{~mm}$ below the ground, the loss determined from the intercepts in Figure 3 differs by $37.3 \mathrm{~dB}$, while attenuation constants were 0.531 and $0.195 \mathrm{~dB} / \mathrm{m}$ below and above ground correspondingly.

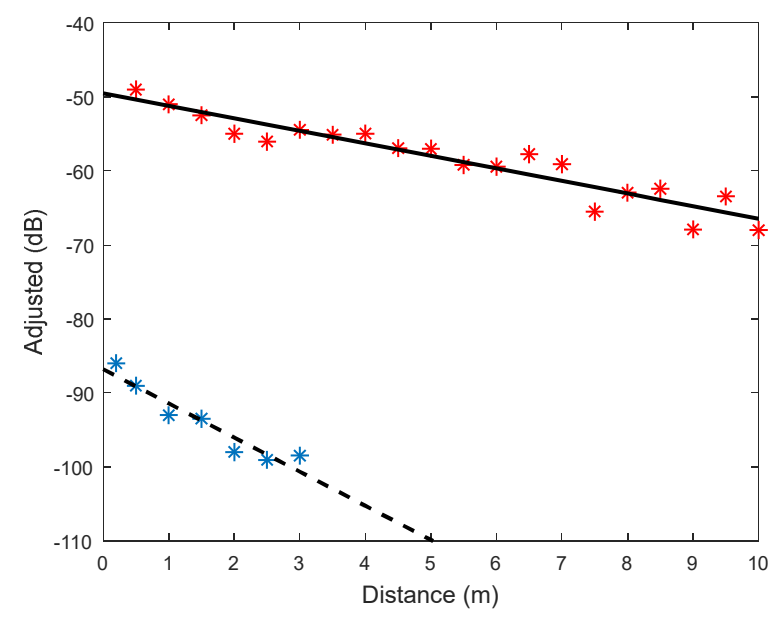

Fig. 3. Measured data and linear fit for the vertical electric field adjusted for distance using (3), at the surface for an on-ground monopole transmitter (continuous line, ${ }^{*}$ ) and a buried cavity slot transmitter (dashed line, ${ }^{*}$ ). 
Table 1. Linear parameters from Equation (3) for the transmitter above and below ground.

\begin{tabular}{|c|c|c|c|c|}
\hline Transmitter & $\begin{array}{c}\text { Slope } \\
(\mathbf{d B} / \mathbf{m})\end{array}$ & $\begin{array}{c}\text { Intercept } \\
(\mathbf{d B})\end{array}$ & $\boldsymbol{\alpha} \mathbf{( d B} / \mathbf{m})$ & $\mathbf{r}^{\mathbf{2}}$ \\
\hline Above ground & -1.695 & -49.5 & 0.195 & 0.89 \\
\hline Below ground & -4.61 & -86.8 & 0.531 & 0.9 \\
\hline
\end{tabular}

\section{CONCLUSIONS}

The radiation from the buried slot antenna suffered significant attenuation when compared with a quarter-wave monopole transmitter above ground. The aluminium box buried $100 \mathrm{~mm}$ below the surface is mechanically and thermally robust under most environmental conditions including:

- Variations in soil moisture including flooding;

- Shallow surface disturbances including the soil compression from motor vehicles, shallow tillage; and

- Bush fire temperatures which might reach $+1500^{\circ} \mathrm{C}$ above ground have been observed to be less than $50^{\circ} \mathrm{C}$ at $100 \mathrm{~mm}$ below the ground.

The deployment of an elevated receiver can increase the received signal strength. Further work is oriented towards improving the radiation characteristics through a more optimised antenna design, and numerical modelling for different top soil conductivities.

\section{REFERENCES}

[1] T. Tamir, "On radio-wave propagation in forest environments", IEEE Trans. $A P$ vol. 15 (6), pp. 806-817, 1967.

[2] M. Hardie and D. Hoyle, "Underground Wireless Data Transmission Using 433-MHz LoRa for Agriculture," Sensors, vol. 19, no. 19, p. 4232, 2019.

[3] U. I. Minhas, I. H. Naqvi, S. Qaisar, K. Ali, S. Shahid, and M. A Aslam, "A WSN for monitoring and event reporting in underground mine environments," IEEE Systems Journal, vol. 12, no. 1, pp. 485496, 2017.
[4] X. Yu, P. Wu, Z. Zhang, N. Wang, and W. Han, "Electromagnetic wave propagation in soil for wireless underground sensor networks," PIER $M$, vol. 30, p. 11-23, 2013

[5] A. Salam, M. C. Vuran, and S. Irmak, "Di-Sense: In situ real-time permittivity estimation and soil moisture sensing using wireless underground communications," Computer Networks, vol. 151, pp. 3141, 2019.

[6] U. Raza and A. Salam, "Wireless underground communications in sewer and stormwater overflow monitoring: Radio waves through soil and asphalt medium", MDPI Information, 2020. doi:10.3390/info11020098.

[7] X. Dong, M.C. Vuran and S. Irmak, "Autonomous precision agriculture through integration of wireless underground sensor networks with center pivot irrigation systems", Ad Hoc Networks, vol. 11, pp. 1975-1987, 2013.

[8] P.R. Bannister, "New simplified formulas for ELF subsurface-tosurface propagation", IEEE J. Ocean. Eng., vol. 9 (3), pp. 154-163, Jul. 1984.

[9] R. W. P. King and M. F. Brown, "Lateral electromagnetic waves along plane boundaries: A summarizing approach," Proc. IEEE, vol. 72, no. 5, pp. 595-611, May 1984

[10] A. Emelyanenko, S.G. O'Keefe, H.G. Espinosa and D.V. Thiel, "Surface field measurements from a buried UHF transmitter: Theory, modelling and experimental results", IEEE Trans. AP. vol. 65(8), pp. 4389-4393, Aug. 2017.

[11] Z. Loni, H.G. Espinosa and D.V. Thiel, "Floating monopole antenna on a tethered subsurface sensor at $433 \mathrm{MHz}$ for ocean monitoring applications", IEEE J. Ocean. Eng., vol. 42 (4), pp. 818-825, Oct. 2017.

[12] O.M. Ketterings and J.M. Bigham, "Soil colour as an indicator of slashand-burn fire severity and soil fertility in Sumatra, Indonesia, Soil Sci.Soc. Am. J., vol 64, pp 1826-1833, Oct. 2000.

[13] M. Fernandez, H.G. Espinosa, D.V. Thiel and A. Arrinda, "Wearable slot antenna at $2.45 \mathrm{GHz}$ for off-body radiation: Analysis of efficiency, frequency shift, and body absorption", Bioelectromagnetics, vol. 29, pp. 25-34, 2018

[14] N.M. Albadri, J.A. Hides, H.G. Espinosa, and D.V. Thiel, "The effect of human tissue on field strength measurements in-vivo using a resonant UHF cavity-backed slot antenna", Bioelectromagnetics, vol. 42, pp. 284-295, 2021.

[15] E.C. Jordan and K.G. Balmain, Electromangetic Waves and Radiating Systems, $2^{\text {nd }}$ ed, Prentice-Hall, Englewood Cliffs, N.J, 1968.

[16] A.D. Watt, VLF Radio Engineering, Pergamon Press, Oxford, 1967. 